\title{
DESIGN, TECNOLOGIA E VALORIZAÇÃO LOCAL: DESENVOLVIMENTO DA COLEÇÃO "MEU PAMPA É JOIA" UTILIZANDO TÉCNICAS DE BENEFICIAMENTO COM MATERIAL GEMOLÓGICO LOCAL.
}

Rosimeri Franck Pichler

Mestre, Universidade Federal do Rio Grande do Sul (UFRGS)

rosi.pichler@gmail.com

Pedro Luiz Juchem

Prof. Dr., Universidade Federal do Rio Grande do Sul (UFRGS)

pedro.juchem@hotmail.com

Resumo: A fim de aliar características presentes na cultura local com os avanços tecnológicos inseridos no contexto da joalheria, este artigo tem como objetivo apresentar o processo de desenvolvimento da coleção de joias "Meu Pampa é joia", que foca na valorização de aspectos da cultura gaúcha, utilizando técnicas de beneficiamento industrial e o serpentinito como material gemológico local. Como resultado, tem-se o relato do processo de desenvolvimento da coleção e especificação dos processos de confecção para cada peça. Foram desenvolvidos colares, pulseiras e brincos, totalizando seis peças. Ao final, conclui-se que é possível desenvolver produtos culturais que valorizem aspectos da identidade local, utilizando-se de técnicas de beneficiamento industriais, e que esta pode ser uma alternativa de gerar desenvolvimento regional.

Palavras-chave: design de joias, valorização local, tecnologia.

\begin{abstract}
To combine characteristics presents in the local culture with technological advances entered in the jewelry context, this article aims to present the development process of the jewelry collection "Meu Pampa é joia", which focuses on the valuation aspects of the gaucho culture, using industrial techniques and the serpentinite as local gemstone. As a result, are presented the collection development process and the specifications of the production process for each jewel. Necklaces, bracelets and earrings were developed, totaling six jewels. Finally, it is concluded that it is possible to develop cultural products that enhance aspects of local identity, using industrial techniques, and that this may be an alternative to generate regional development.
\end{abstract}

Keywords: jewelry design, local value, technology. 


\section{INTRODUÇÃO}

O design no Brasil, desde sua constituição oficial nos anos 60 , sustentou 0 modelo racional-funcionalista moderno com o intuito de guiar o país rumo à industrialização, e sair da condição de periferia, subdesenvolvimento e pobreza. Tal fator ocasionou a não inserção de símbolos da cultura local brasileira na produção de seus bens materiais pela indústria, por não serem compreendidos no momento, como uma forma de promover o desenvolvimento no país. Somente com a chegada dos ideais da cultura pós-moderna é que houve um impulso por parte dos designers brasileiros em ir contra o design local vigente. Assim, na metade dos anos 90 o design local despontou como nova cultura projetual, iniciando no Brasil o surgimento de um design plural, que tem origem e inspiração nas diversas culturas do país (LAGES; BRAGA; MORELLI, 2004).

Desde então, os estudos referentes a valorização de culturas locais se intensificaram, no design e outras áreas do conhecimento, também devido a um fato contrário ao que se pensava no advento da era da globalização, cujo fenômeno caracteriza-se pela compressão espaço-tempo, aproximando e intensificando cada vez mais as trocas materiais e culturais (HARVEY, 1992). Porém, percebeu-se um movimento oposto, onde a necessidade é de diferenciação dos demais, de resgatar elementos que identificam o local, os costumes, as crenças e os hábitos que envolvem o indivíduo representado. O design, neste contexto, assume a função básica de tornar os produtos comunicáveis em relação às funções simbólicas e ao uso dos mesmos, tornando essa prática profissional decisiva no desenvolvimento de suportes materiais, relações simbólicas e práticas dos indivíduos nas sociedades (ONO, 2004). O designer, segundo Krucken (2009), assume o papel de auxiliar os territórios na tarefa de transpor suas culturas e conhecimentos singulares em produtos, mediando produção e consumo, tradição e inovação, qualidades locais e relações globais.

Quanto ao setor joalheiro no Brasil, devido ao seu potencial gemológico e reconhecimento como um dos grandes produtores mundiais de gemas (LICCARDO; CHODUR, 2009), este vem apresentando grande crescimento e recebendo muitos investimentos, tanto em tecnologia como em pesquisas. No Rio Grande do Sul, conforme Rempel (2010), o setor joalheiro encontra-se em uma fase de grandes avanços no sentido de modernizar seus processos por meio do emprego de novas tecnologias, deixando a produção artesanal para incorporar a produção industrial, desde o pequeno produtor até grandes empresas. De acordo com Duarte et al (2010), o emprego de tecnologias inovadoras confere às joias acabamentos refinados e diferenciados, agregando valor a novos materiais e ampliando as possibilidades de criação do designer. Neste sentido, percebe-se a importância da atuação do design no desenvolvimento de produtos de melhor qualidade, preços competitivos e valor agregado, incorporando às peças a diversidade das gemas brasileiras (IBGM, 2013). Além disso, a participação do designer no setor é de grande importância no que tange a criação de objetos diferenciados e que, utilizando-se de gemas regionais, promova a criação de peças com uma identidade local (JUCHEM et al, 2009).

Mediante o panorama apresentado, compreende-se a necessidade de aliar características presentes na cultura local, com os avanços tecnológicos inseridos no contexto da joalheria para agregar valor simbólico e comercial às peças. Assim, este artigo tem como objetivo apresentar o processo de desenvolvimento de uma coleção 
de joias com foco na valorização de aspectos da cultura local, utilizando técnicas de beneficiamento de cunho industrial, e tendo o serpentinito como material gemológico local. Como metodologia de projeto utilizou-se uma mescla dos métodos propostos por Lobah (2001) e Baxter (2000), além de um quadro de apoio ao desenvolvimento de produtos identitários proposto por Pichler (2014).

\section{REFERENCIAL TEÓRICO}

\subsection{0 desenvolvimento de produtos de referência cultural}

Mediante esta relação do design com a materialização das práticas sociais e culturais de determinados territórios, é que se conceitua o desenvolvimento de produtos culturais. Um produto cultural caracteriza-se pelo tipo de valor agregado, seja ele um bem ou um serviço, possuindo assim, além de valor econômico e mercadológico, o valor cultural ligado a um grupo em particular, cujos elementos o distinguem de outros grupos (THROSBY, 2008).

Valor cultural agregado, segundo Arantes (2004), são os objetos, estilos e atividades que, por meio do estudo dos códigos culturais vigentes, caracterizam determinados grupos sociais mediante o reconhecimento de signos e significações presentes nos mesmos. Ou seja, um produto, para ser considerado de valor cultural agregado, deve se utilizar de uma 'rede' estabelecida de signos e símbolos que determinam o local, a partir do estudo de suas referências. As referências, portanto, são sentidos atribuídos aos objetos, práticas sociais e lugares, que foram apropriados pela cultura na construção da identidade de determinado grupo, e que popularmente são chamadas de 'raízes da cultura' (ARANTES, 2004).

A fim de reunir tais elementos da cultura e compor assim uma 'rede' de signos e símbolos culturais para nortear o processo de desenvolvimento de produtos culturais, Pichler (2014) organizou-os em duas colunas, uma destacando as categorias identitárias e outra destacando as referências culturais a serem exploradas e transpostas ao produto a ser desenvolvido. Esta organização teve como base conhecimentos provindos da literatura, os quais foram divididos em categorias e referências, conforme apresentado no Quadro 1. 
Quadro 1 - Estudos da literatura sobre categorias identitárias e referências culturais.

\begin{tabular}{|c|c|c|}
\hline Autor & Categorias & Referências \\
\hline $\begin{array}{l}\text { Cabral } \\
(2004)\end{array}$ & & $\begin{array}{l}\text { Formas de expressão; } \\
\text { Modos de criar, fazer, viver; } \\
\text { Criações científicas, artísticas e tecnológicas; } \\
\text { Obras, objetos, documentos, edificações e } \\
\text { demais espaços destinados às manifestações } \\
\text { artístico-culturais; } \\
\text { Conjuntos urbanos e sítios de valor histórico, } \\
\text { paisagístico, artístico, arqueológico, } \\
\text { paleontológico, ecológico e científico. }\end{array}$ \\
\hline $\begin{array}{l}\text { Niemeyer } \\
\text { (2007) }\end{array}$ & $\begin{array}{l}\text { Configuração estética; } \\
\text { Materiais e processos produtivos } \\
\text { utilizados; } \\
\text { Composição e organização das partes; } \\
\text { Cores empregadas; } \\
\text { Dores que exala; } \\
\text { Sons que produz; } \\
\text { Qualidade. }\end{array}$ & $\begin{array}{l}\text { Origem cultural; } \\
\text { Origem Geográfica; }\end{array}$ \\
\hline $\begin{array}{l}\text { Barroso } \\
(2008)\end{array}$ & $\begin{array}{l}\text { Reporta ao local de origem; } \\
\text { Uso de matérias primas da região; } \\
\text { Uso de técnicas típicas da região; } \\
\text { Uso de elementos simbólicos }\end{array}$ & $\begin{array}{l}\text { Arte e Arquitetura } \\
\text { Artefatos } \\
\text { Folclore } \\
\text { Iconografia Fauna e Flora }\end{array}$ \\
\hline
\end{tabular}

Fonte: Elaborado pelo autor.

Com base neste quadro, as categorias e referências foram agrupadas, dando origem a Figura 2, que apresenta as referências a serem buscadas no local e as categorias do produto que estas podem ser exploradas. Assim, o designer pode utilizar estas informações para guiar o processo de desenvolvimento de produtos identitários, de acordo com as potencialidades e singularidades do local a ser representado. Por exemplo, há locais em que a iconografia flora e fauna é mais representativa, em outros, os lugares, sua arquitetura e edificações são mais representativos. Neste ponto, cabe ao designer definir estes elementos e, conforme as categorias identitárias, transpor tais elementos ao produto identitário.

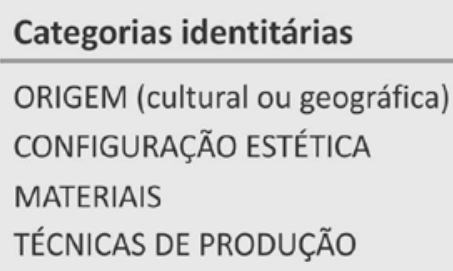

Referência cultural

(modos de criar, fazer, viver) SABERES (linguagem, arte, cores, formas) EXPRESSÃO (celebrações, danças, cantos) FOLCLORE (paisagens, edificações) LUGARES (artesanato, obras, objetos).ARTEFATOS (fauna e flora) RIQUEZAS NATURAIS

Figura 1 - Categorias identitárias e referências culturais no desenvolvimento de produtos. Fonte: PICHLER (2014).

\subsection{Serpentinito como material gemológico local}

O serpentinito é considerada uma gema ornamental rara pela Swiss Gemological Society (SGS, 1988), por existirem poucos depósitos deste material no planeta. No interior do Rio Grande do Sul ocorrem depósitos dessa rocha, em terrenos de embasamento cristalino (Escudo sul-rio-grandense), onde estão as rochas mais antigas do estado (Figura 2a). Esse conjunto de rochas corresponde a idades entre 700 
e 750 Ma (milhões de anos) e ocorrem como vários corpos alongados com a largura variando de metros a dezenas de metros e comprimento da ordem de algumas centenas de metros.

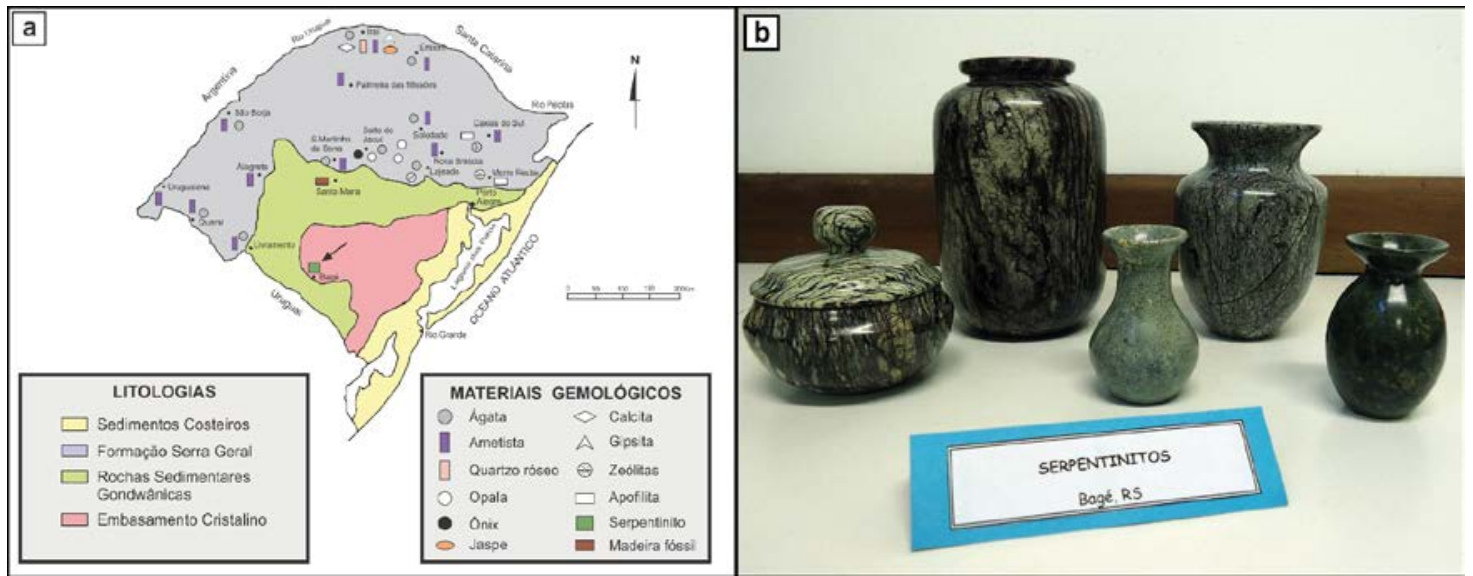

Figura 2 - Mapa dos principais depósitos gemológicos do Rio Grande do Sul, com indicação da região onde já foi beneficiado o serpentinito (a). Peças fabricadas pelo artesão William Horvath (b).

Fonte: a - adaptado de Juchem et al (2007); b - PICHLER (2014).

Até o momento, obteve-se apenas um registro de beneficiamento desse material na cidade de Bagé, interior do Rio Grande do Sul, pelo artesão William Horvath que produzia objetos ornamentais desde a década de 70 (vasos, porta objetos, entre outros) com alto padrão de qualidade (Figura 2b). Apesar disso, o serpentinito é pouco conhecido no estado, pois todas as peças eram exportadas e não há conhecimento de outro uso comercial deste material (JUCHEM et al, 2009). Após o falecimento do artesão no ano de 1996, as peças pararam de ser produzidas pois ninguém da família deu continuidade ao ofício.

A utilização do serpentinito como gema ornamental não é proibida por lei, apesar de possuir em sua composição o asbesto do tipo crisotilo. Asbesto é um termo comercial utilizado para se referir de forma generalizada a seis espécies de minerais fibrosos: os do grupo das serpentinas (crisotilo) e os do grupo dos anfibólios (crocidolita, amosita, antofilita, tremolita e acinolita). O asbesto composto por crisotilo ( $95 \%$ do asbesto utilizado no mundo), é diferente do asbesto do grupo dos anfibólios ( 4 a $5 \%$ do asbesto utilizado no mundo) proibidos de serem utilizados pela legislação brasileira, porque estes últimos são duros, retos e pontiagudos, enquanto que o crisotilo é curvo, flexível e sedoso. Conforme a lei $n^{\circ} 9.055$ de 01 de junho de 1955, Art. $2^{\circ}$, as rochas que contenham crisotilo, podem ser extraídas, comercializadas e utilizadas, desde que estejam de acordo com as exigências desta mesma Lei, com relação às normas de segurança, higiene e saúde dos envolvidos em sua extração, pesquisa e comercialização, não apresentando desta forma riscos à saúde de quem extrai, pesquisa, comercializa ou utiliza este material.

\section{PROCEDIMENTOS METODOLÓGICOS}

Primeiramente, destaca-se que este artigo traz parte dos resultados de uma pesquisa de dissertação, na qual realizou-se o estudo de técnicas de beneficiamento do Serpentinito para uso como material gemológico local aplicado ao design de joias. 
Neste trabalho, foram estudados e definidos parâmetros de uso para cinco técnicas de beneficiamento: gravação a laser; corte por jato d'água e por serra diamantada; lixamento; e resinagem. Os parâmetros estabelecidos foram utilizados como requisitos na confeç̧ão da linha de joias, a qual é apresentada neste artigo. Na Figura 3 é apresentado o contexto em que está inserido o presente artigo, com descrição das etapas adotadas no desenvolvimento da linha.

\begin{tabular}{|c|c|}
\hline \multicolumn{2}{|c|}{ DISSERTAÇÃO DE MESTRADO } \\
\hline Estudo das técnicas de beneficiamento & Desenvolvimento da linha de joias \\
\hline CONHECER & PREPARAÇÃO \\
\hline $\begin{array}{l}\text { Estudo dos aspectos da } \\
\text { valorização local }\end{array}$ & $\begin{array}{l}\text { Levantamento dos referenciais } \\
\text { culturais locais; }\end{array}$ \\
\hline TESTAR & $\begin{array}{l}\text { Elaboraçăo dos paineis visuais: } \\
\text { Temático - Fstilo deVida - Expressão do produto. }\end{array}$ \\
\hline ANALISAR & Estudos das tendências em joalheria \\
\hline DEFINIR & Definição dos requisitos de projeto \\
\hline $\begin{array}{l}\text { Definição dos parâmetros } \\
\text { para cada técnica de } \\
\text { beneficiamento }\end{array}$ & $\begin{array}{l}\text { GERAÇÃO } \\
\text { Geração de alternativas }\end{array}$ \\
\hline & $\begin{array}{l}\text { AVALIAÇAO } \\
\text { Escolha e definição da coleção }\end{array}$ \\
\hline $\begin{array}{l}\text { Contexto } \\
\text { do artigo }\end{array}$ & $\begin{array}{l}\text { EXECUÇÃO } \\
\text { Confecção das peças }\end{array}$ \\
\hline
\end{tabular}

Figura 3 - Contexto do artigo e etapas da metodologia de projeto adotada. Fonte: Elaborado pelo autor.

O processo de desenvolvimento da linha de joias se deu em quatro fases, conforme proposto por Lobach (2001): Preparação, Geração, Avaliação e Execução. Na etapa de Preparação foram levantadas informações e imagens referenciais do local a serem valorizados nas peças, de acordo com as categorias e referências proposto por Pichler (2014). Ao final desta etapa foram definidos os requisitos de projeto, onde foram incorporados os parâmetros das técnicas de beneficiamento definidos na pesquisa. $\mathrm{Na}$ etapa de Geração, foram confeccionados os painéis semânticos, propostos por Baxter (2000) e geradas as alternativas. Na etapa de Avaliação, foram selecionadas as alternativas e na etapa de Execução as peças escolhidas foram produzidas.

\section{DESENVOLVIMENTO DA COLEÇÃO DE JOIAS}

Como ponto de partida ao processo de desenvolvimento da linha de joias, fezse o preenchimento do quadro de categorias identitárias e referências culturais que poderão ser explorados nas peças e que nortearão a confecção dos painéis referenciais (Quadro 2).

Quadro 2 - Elementos locais utilizados como referenciais na confecção da coleção de joias.

\begin{tabular}{|l|c|l|}
\hline \multicolumn{1}{|c|}{ CATEGORIA } & USO & \multicolumn{1}{c|}{ ELEMENTO } \\
\hline Origem & Sim & Pampa gaúcho \\
\hline Configuração & Sim & Formas; Cores \\
\hline Materiais & Sim & Serpentinito \\
\hline Técnicas & Não & \\
\hline
\end{tabular}

Fonte: Elaborado pelo autor

\begin{tabular}{|l|l|l|}
\hline \multicolumn{1}{|c|}{ REFERENCIAL } & USO & \multicolumn{1}{c|}{ ELEMENTO } \\
\hline Saberes & Não & \\
\hline Expressão & Sim & Cores \\
\hline Folclore & Sim & Indumentária gaúcha \\
\hline Lugares & Sim & Pampa \\
\hline Artefatos & Sim & Acessórios \\
\hline Riquezas naturais & Sim & Fauna; Flora \\
\hline
\end{tabular}


Tendo os elementos locais definidos, elaborou-se o painel temático, do qual serão extraídas as referências visuais para gerar as alternativas, além dos painéis de expressão do produto e de estilo de vida do usuário (Figura 4). No painel temático, tem-se: o gaúcho que vive no Pampa, sua indumentária e seus artefatos, acessórios utilizados na lida do campo; a flor de corticeira e o capim-do-pampa, espécies da flora muito presentes na paisagem local; e o João de Barro, um dos principais representantes da fauna do Pampa. Para a expressão do produto, tem-se a intenção de trabalhar uma linguagem rústica e natural, com o uso de técnicas industriais de confecção das peças. Como estilo de vida do usuário, destina-se a pessoas modernas, mas que gostam de um toque natural.
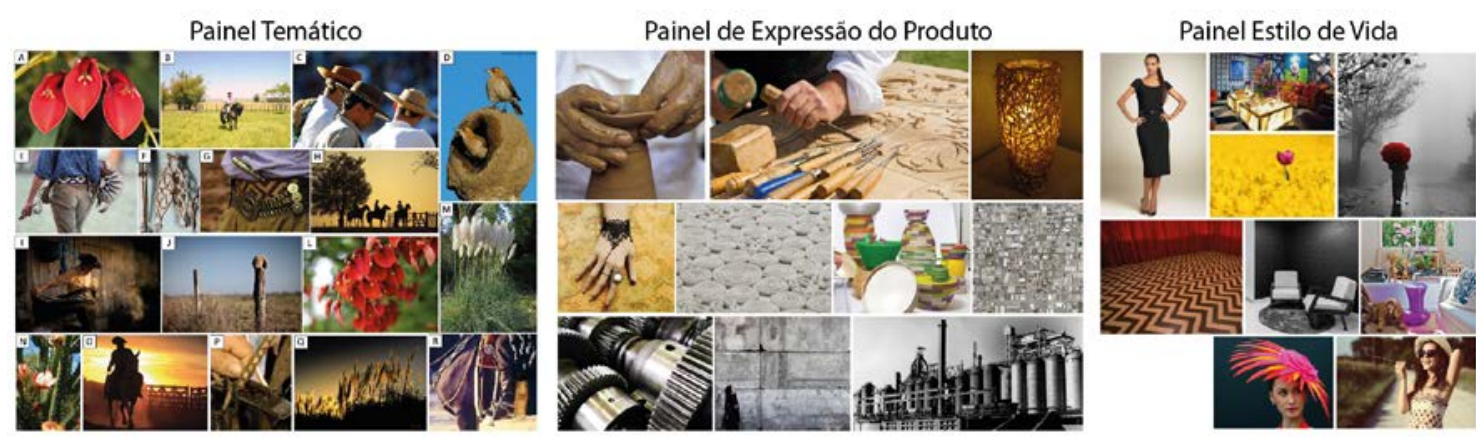

Figura 4 - Painel temático, painel de expressão do produto e painel de estilo de vida do usuário.

Fonte: Elaborado pelo autor

Outro painel utilizado foi o de tendência em joalheria para 2015 (ano seguinte ao de desenvolvimento das peças), montado a partir do estudo de tendências publicado pela IBGM em parceria com o SEBRAE (IBGM, 2014). Para cada tendência foram selecionadas imagens representativas para compor o painel de tendências (Figura 5). Os quatro grandes conceitos foram: Essencialismo (simples, geométricas, limpas e futuristas), Memory games (nostálgicas, remetendo a flores, animais, romantismo e suavidade), Very Important Classics (renovam os clássicos com novos referenciais temáticos) e Ludicidade (vivas, surrealistas, com elementos contemporâneos).
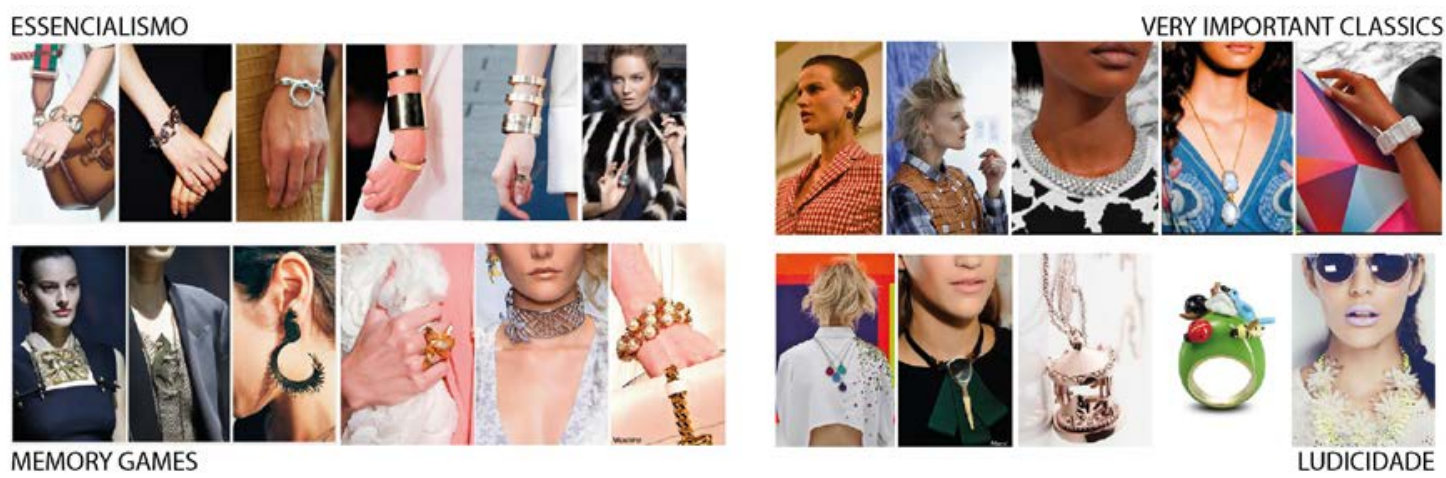

Figura 5 - Painel dos quatro conceitos tendência em 2015 para joalheria.

Fonte: Elaborado pelo autor

Após a conclusão desta fase de levantamento e estudo dos referências culturais e tendências em joalheria, foram organizados os requisitos de projeto. No Quadro 3, os requisitos foram divididos em: Configuração, requisitos relacionados a forma e estética da joia; Materiais, requisitos para materiais de apoio e acessórios; e Fabricação, 
requisitos relacionados as técnicas e parâmetros que poderão ser explorados na geração de alternativas.

Quadro 3 - requisitos de projeto para criação da linha “Meu Pampa é joia”.

\section{REQUISITOS DE PROJETO}

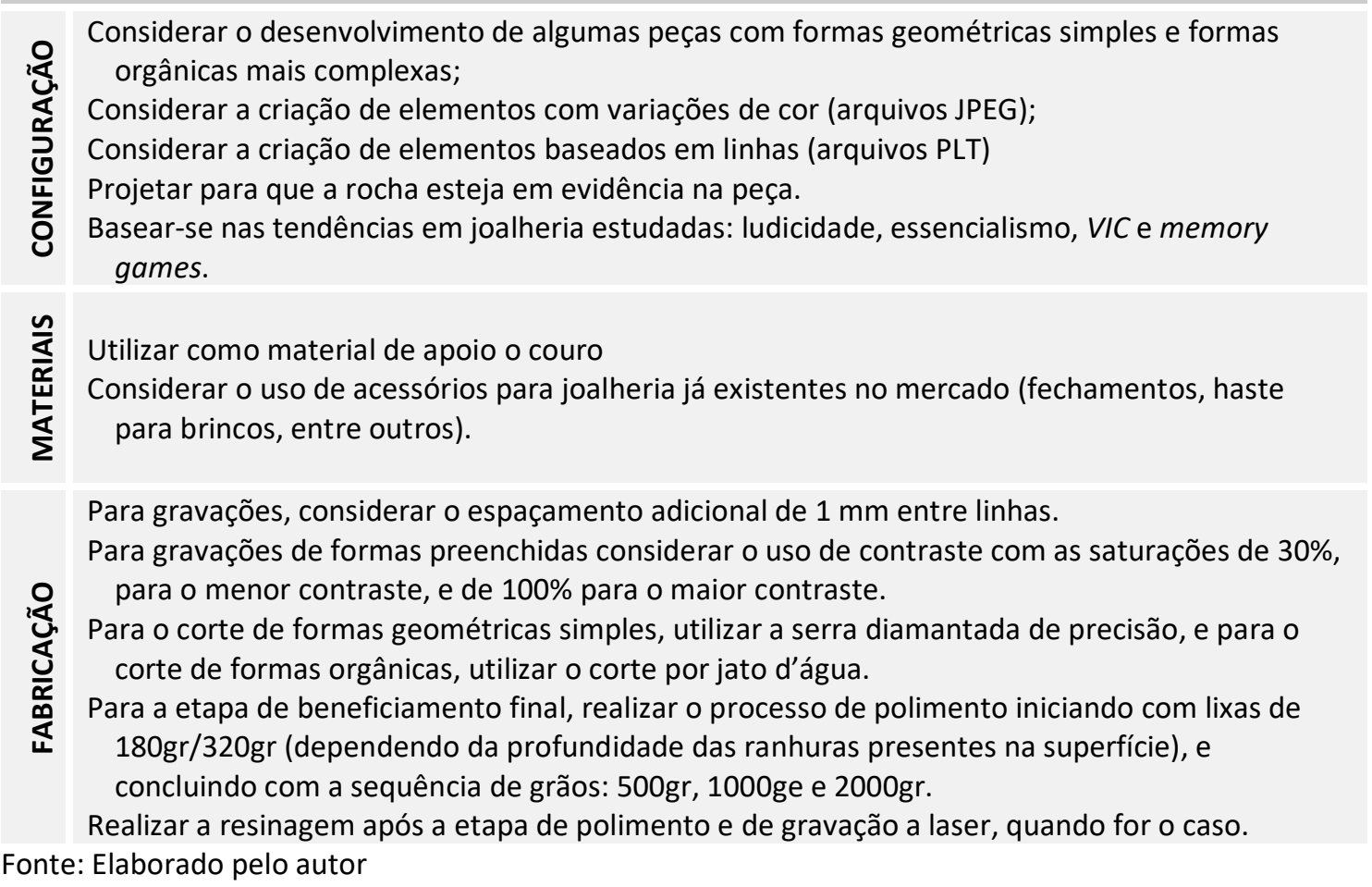

Tendo concluída a etapa de Preparação, partiu-se para a geração de alternativas que culminou na definição das peças a comporem a coleção. Assim, a coleção será composta por cinco peças, são elas: colar e brinco "Corticeira", colar e pulseira "João de Barro", colar "Capim-do-Pampa" e colar "Pampeano". Nos itens que se seguem, são especificados os processos de confecção de cada peça, correspondente a etapa de Execução do projeto.

\subsection{Conjunto Corticeira}

O conjunto Corticeira é composto por colar e brinco. O processo de confecção da peça iniciou com o corte da peça na serra diamantada de precisão (velocidades: 100 rpm, $200 \mathrm{rpm}$ e $100 \mathrm{rpm}$ ), seguido do lixamento com carbeto de silício (320gr, 500gr, $1000 \mathrm{gr}, 2000 \mathrm{gr})$. A técnica principal utilizada foi a gravação a laser de arquivo em JPEG com saturação de preto de $30 \%$ e $100 \%$ (potência de $60 \mathrm{~W}$, lente $10 \times 10 \mathrm{~cm}$ e velocidade de $8 \mathrm{~m} / \mathrm{min}$ ), na superfície da peça já cortada e lixada. Por fim, fez-se a montagem da peça utilizando tiras de couro, na cor Cranberry com espessura de $4 \mathrm{~mm}$, e peças em níquel: terminal e fecho lagosta para fechamento do colar, entremeios, e base de brinco anzol. Abaixo, são apresentadas as especificações para melhor entendimento das peças e a foto da peça finalizada (Figura 6). 


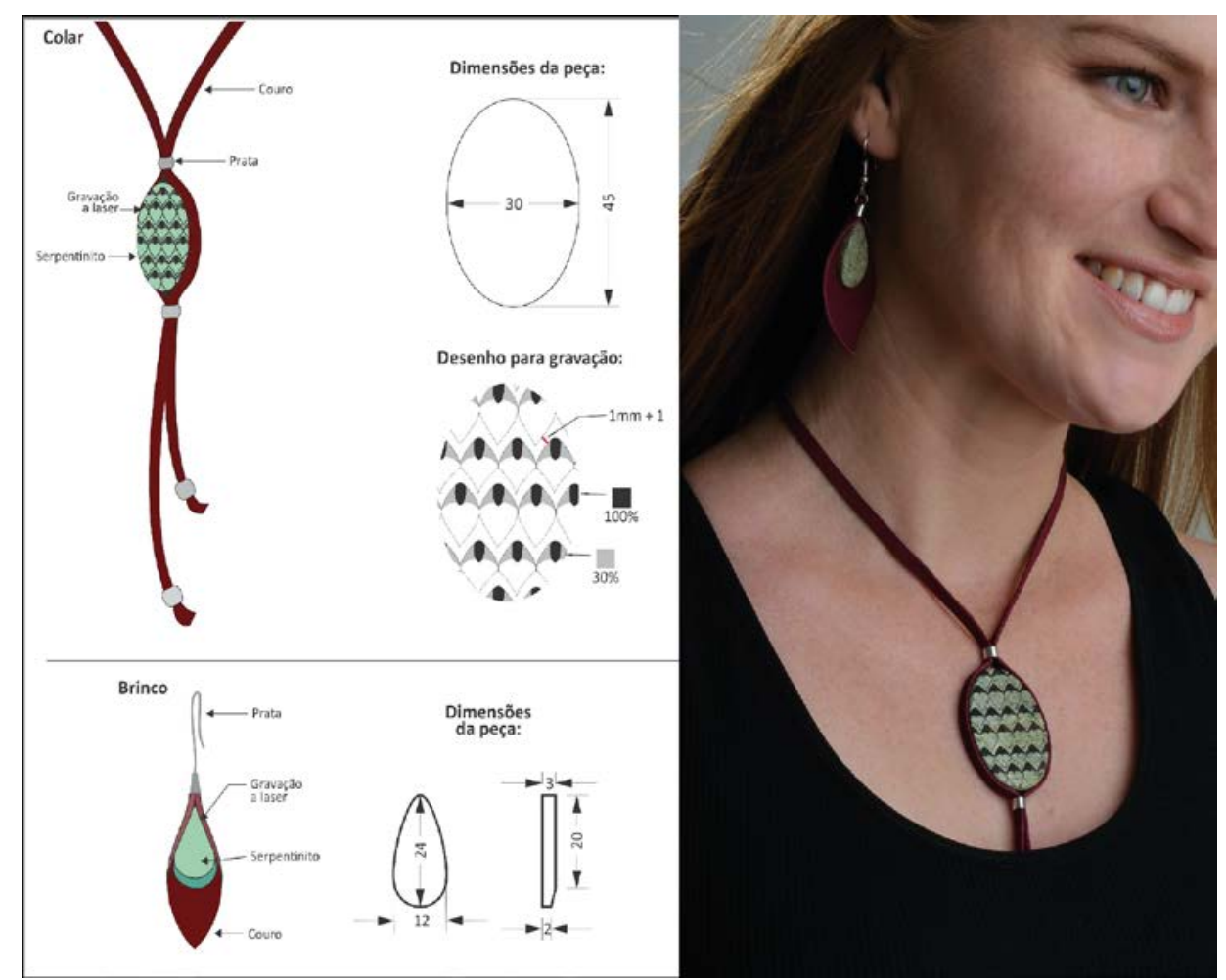

Figura 6 - especificações do colar e brinco "Corticeira", e foto da peça finalizada. Fonte: Elaborado pelo autor.

\subsection{Conjunto João de Barro}

O conjunto "João de Barro" é composto por colar e pulseira. O processo de confecção iniciou com o corte do formato da peça na máquina de corte por jato d'água (Velocidade: $100 \%$ (200 mm/s (curvas) e $250 \mathrm{~mm} / \mathrm{s}$ (retas) e Diâmetro do bico: 1,2 $\mathrm{mm}$ ), seguindo para a etapa de lixamento com carbeto de silício (320gr, 500gr, 1000gr, 2000gr) e resinagem da peça. Por fim, na etapa de montagem, utilizou-se corrente de níquel para o colar com acabamento na parte inferior da peça em couro marrom claro. Para a pulseira utilizou-se uma tira de couro marrom claro e corrente com fechamento em níquel. Abaixo, são apresentadas as especificações para melhor entendimento das peças e a foto da peça finalizada (Figura 7). 


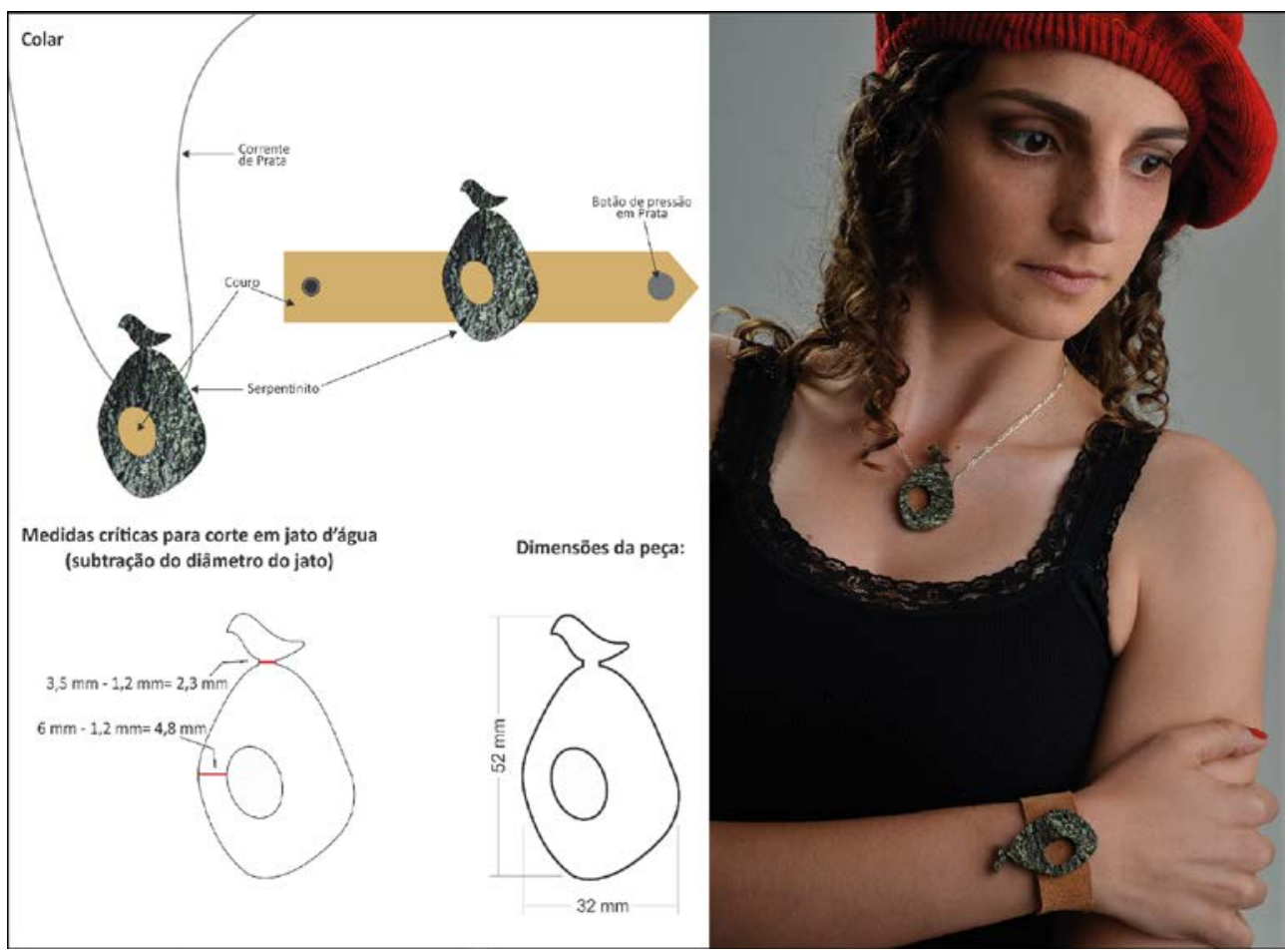

Figura 7 - especificações do colar e pulseira "João de Barro", e foto da peça finalizada. Fonte: Elaborado pelo autor.

\subsection{Colar "Capim-do-Pampa"}

O processo de confecção do colar iniciou com o corte da peça retangular na serra diamantada (velocidade de $100 \mathrm{rpm}, 150 \mathrm{rpm}$ e $100 \mathrm{rpm}$ ), seguinda da etapa de lixamento da peça com carbeto de silício (320gr, 500gr, 1000gr, 2000gr). Tendo a superfície da peça preparada, fez-se a gravação a laser em linhas (potência de 60W, lente $10 \times 10 \mathrm{~cm}$ e velocidade de $2 \mathrm{~m} / \mathrm{min}$ ), com arquivo PLT e espaçamento entre linhas de pelo menos $1 \mathrm{~mm}$. Após a gravação a peça recebeu o beneficiamento final em resina acrílica. Para finalizar a peça, utilizou-se couro em tom marrom escuro na parte frontal e posterior da peça, bem como para a confecção da corrente. Para o fechamento, ponteira e fecho em ouro velho foram utilizados. Abaixo, são apresentadas as especificações para melhor entendimento das peças e a foto da peça finalizada (Figura 8). 


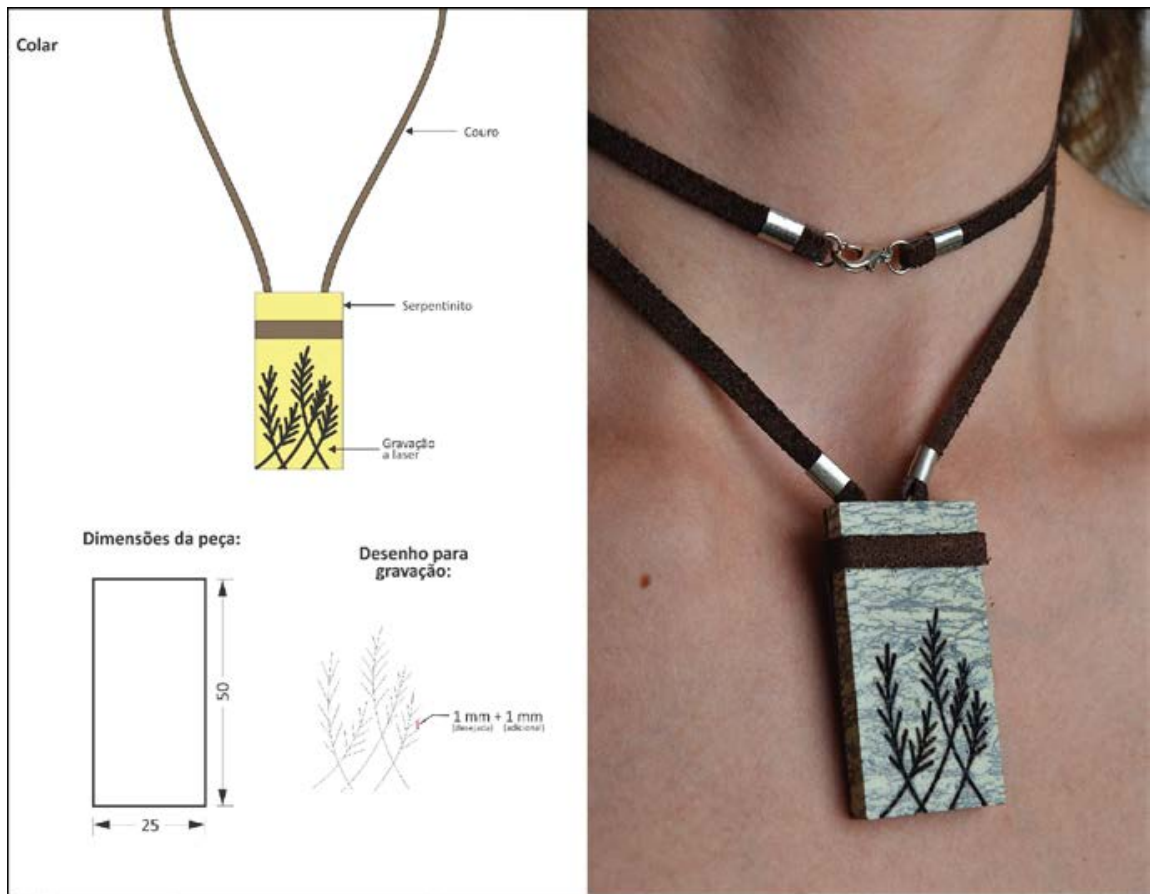

Figura 8 - especificações do colar “" Capim-do-Pampa” e foto da peça finalizada. Fonte: elaborado pelo autor.

\subsection{Colar Pampeano}

O processo de confecção do colar iniciou com o corte da peça na serra diamantada (velocidade de $100 \mathrm{rpm}, 300 \mathrm{rpm}$ e $100 \mathrm{rpm}$ ), seguindo da etapa de lixamento da peça com carbeto de silício (320gr, 500gr, 1000gr, 2000gr) e acabamento em resina acrílica. Para finalização, utilizou-se couro na cor preta e ponteira para fechamento em níquel. Abaixo, são apresentadas as especificações para melhor entendimento das peças e a foto da peça finalizada (Figura 9).

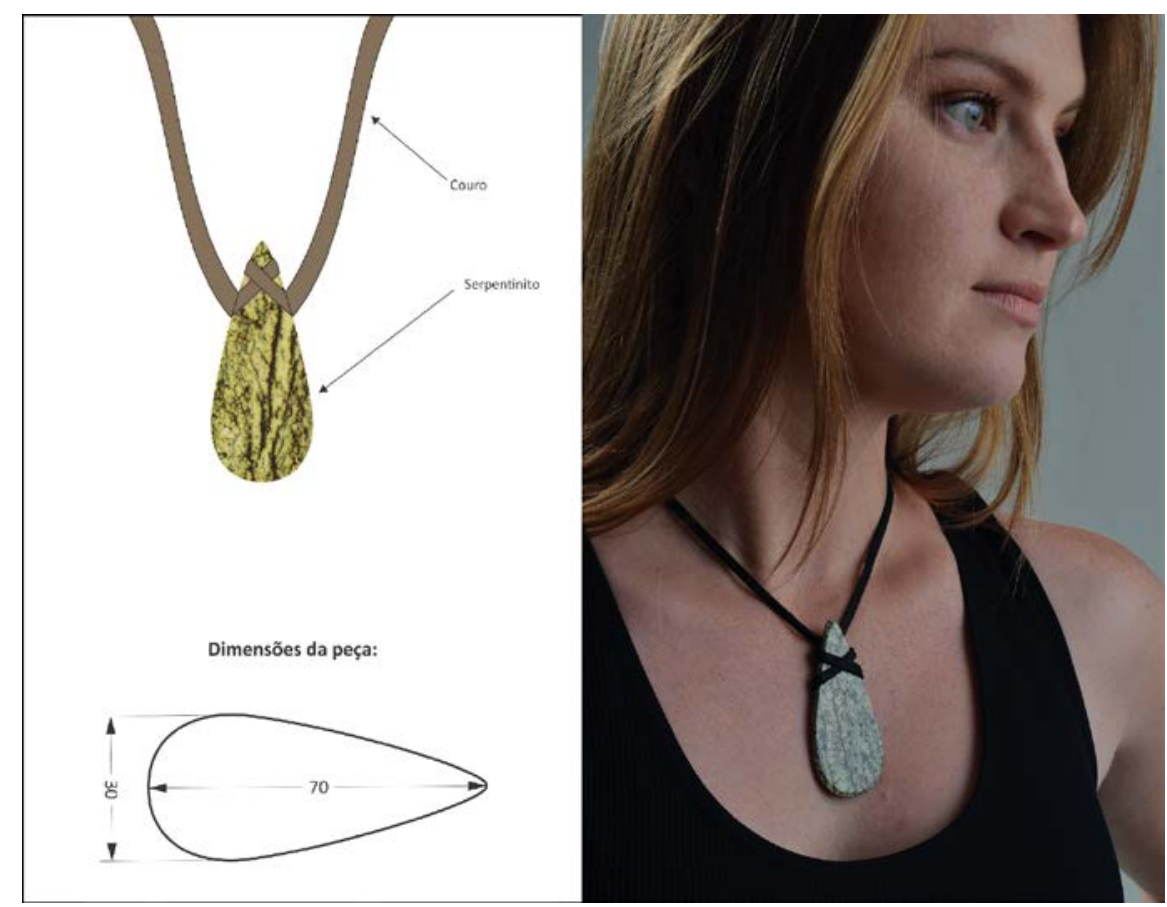

Figura 9 - especificações do colar "Pampeano" e foto da peça finalizada.

Fonte: elaborado pelo autor. 


\section{CONCLUSÃO}

O processo de retorno às origens e busca pela valorização de aspectos culturais e locais em produtos, fenômeno já discutido por muitos autores, é também uma forma de resgatar a competitividade de mercados locais frente aos avanços tecnológicos e às produções em massa dos mercados nacionais e internacionais. Desta forma, o desenvolvimento de produtos locais não exclui a necessidade de incorporar em seus processos produtivos, tecnologias que venham a melhorar a qualidade, aumentar a produtividade e as possibilidades de aplicação.

No caso dos materiais gemológicos, o uso de tecnologias em seu beneficiamento acarreta em um aumento significativo do seu preço de venda em comparação à venda do material bruto. O serpentinito é um material com grande potencial comercial e que, se beneficiado, pode ser empregado na confecção de uma grande variedade de produtos, devido a sua estética e propriedades. Neste artigo, buscou-se referenciar a região da campanha do Rio Grande do Sul (Pampa gaúcho), pelo fato desta rocha ocorrer nesta região. O beneficiamento e exploração comercial deste material pode representar um ramo de investimento e de desenvolvimento regional, promovendo emprego e renda à população local, além de incentivar o desenvolvimento de outros setores, como: universidades, centros tecnológicos, turismo e comércio.

\section{AGRADECIMENTOS}

Os autores agradecem à CAPES e ao CNPq; ao Programa de Pós-Graduação em Design da UFRGS; aos laboratórios LdSM e LACER da UFRGS; ao CTPedras de Soledade/RS; aos Profs. Drs. Lauren da Cunha Duarte, Ruth Hinrichs, Clóvis Gonzatti e Mariana Kuhl Cidade; à Thomas Zibetti; à família Horvath; e às modelos Patrícia Franck Pichler e Fernanda Sulzbach.

\section{REFERÊNCIAS}

ARANTES, A. Cultura e territorialidade em políticas sociais. In: LAGES; BRAGA; MORELLI (Org). Territórios em movimento: cultura e identidade como estratégias de inserção competitiva. 1ạ Ed. Rio de Janeiro: Relume Dumará / Brasília, DF: SEBRAE, 2004.

BARROSO, E. Quase quatro décadas de design. Publicado em: 2008. Disponível em: $<$ http://eduardobarroso.blogspot.com/2008/05/quase-quatro-dcadas-dedesign.html>. Acesso em: 20 ago 2013.

BAXTER, M. Projeto de produto: guia prático para o desenvolvimento de novos produtos. 2a Ed. Edgard Blücher: São Paulo, 2000.

BRASIL. Lei 9.055, de 01 de junho de 1995. Publicada no Diário Oficial da União em 02 de junho de 1995.

CABRAL, F. G. S. Patrimônio cultural e desenvolvimento nacional: o potencial dos bens de natureza imaterial. In: LAGES; BRAGA; MORELLI (Org). Territórios em movimento: cultura e identidade como estratégias de inserção competitiva. 1a Ed. SEBRAE: Brasília, 2004.

DUARTE, L. C. et al. Técnicas Inovadoras e Materiais Naturais em Joalheria no Laboratório de Design e Seleção de Materiais. In: Tecnologias para o setor de gemas, 
joias e mineração. Léo Afraneo Hartmann; Juliano Tonezer da Silva (Org.).

IGEO/UFRGS: Porto Alegre, 2010.

HARVEY, D. Condição pós-moderna: uma pesquisa sobre as origens da mudança cultural. 20ā Ed. Edições Loyola: São Paulo, 2010, 349 p.

IBGM. Características da cadeia produtiva. Disponível em:

<http://www.ibgm.com.br/info_cadeia_produtiva.php>. Acesso em: 04 out. 2013.

Pesquisa da indústria joalheira brasileira. 2013. Biblioteca digital. Disponível em: <http://www.ibgm.com.br/admin/_upload/biblioteca/documento/724IBGMPesquisaindustria-2013.pdf>. Acesso em: 01 jul. 2014.

JUCHEM, P. L. et al. Potencial gemológico da região sul do Brasil. Anais de evento. I SDGEM: Soledade, 2009.

KRUCKEN, L. Design e território: valorização de identidades e produtos locais. Estúdio Nobel: São Paulo, 2009.

LAGES, V.; BRAGA, C.; MORELLI, G. (Org). Territórios em movimento: cultura e identidade como estratégias de inserção competitiva. 1a Ed. Rio de Janeiro: Relume Dumará / Brasília, DF: SEBRAE, 2004.

LICCARDO, A.; CHODUR, N. L. Turismo mineral no Brasil: gemologia e geoturismo. Anais de evento. I SDGEM: Soledade, 2009.

LÖBACH, B. Design Industrial: bases para a configuração de produtos industriais. Edgard Blücher: São Paulo, 2001.

NIEMEYER, L. Elementos de semiótica aplicados ao design. Rio de Janeiro: 2AB, 2007.

ONO, M. M. Design, cultura e identidade, no contexto da globalização. Revista Design em foco, julho-dezembro, vol I, n. 1. p. 53-66, 2004.

PICHLER, R. F. Design, tecnologia e valorização local: estudo de técnicas de beneficiamento em serpentinito para uso como material gemológico aplicado ao design de joias. Dissertação (Mestrado). Universidade Federal do Rio Grande do Sul, Escola de Engenharia, Programa de Pós-Graduação em Design, Porto Alegre-RS, 2014.

REMPEL, C. A joalheria moderna no Rio Grande do Sul. In: HARTMANN, L. A.; SILVA, J. T. da. (Org.). Tecnologias para o setor de gemas, joias e mineração. IGEO/UFRGS: Porto Alegre, 2010.

SGS (Swiss Gemological Society). 1988. Mapa Mundial de depósitos de gemas.

THROSBY, D. Introduction and Overview. In: GINSBURGH, V. A.; THROSBY, D. (Eds.). Handbook of the economics of art and culture. 2. ed. Oxford: North-Holland Elsevier, 2008. p. 3-24. 